\title{
Mobilidade na periferia metropolitana fluminense: transporte ativo posto à prova em São João de Meriti, RJ
}

\author{
Mobility in Rio de Janeiro metropolitan periphery: active transportation \\ challenges in São João de Meriti, RJ
}

Marcelo Mourão Pereira Costa[a] [1], Denise de Alcantara[a] (B)

[a] Universidade Federal Rural do Rio de Janeiro (UFRRJ), Rio de Janeiro, RJ, Brasil

Como citar: Costa, M. M., \& Alcantara, D. (2020). Mobilidade na periferia metropolitana fluminense: transporte ativo posto à prova em São João de Meriti, RJ. urbe. Revista Brasileira de Gestão Urbana, 12, e20190286. https://doi.org/10.1590/2175-3369.012.e20190286

\section{Resumo}

Este artigo apresenta investigação sobre cenários de mobilidade urbana em São João de Meriti, município metropolitano fluminense. Com a maior densidade demográfica do estado e um dos mais baixos índices de bem-estar urbano (IBEU) nacionais, a 'cidade-dormitório' define-se pelo movimento pendular centro-periferia de sua força de trabalho. A pesquisa qualitativa de cunho empírico busca identificar a estrutura do sistema de redes e fluxos viários, em múltiplas escalas de acessibilidade urbana; compreender a realidade local, políticas públicas e ações de planejamento - ferrovia, explosão demográfica, abertura de rodovias e industrialização; e articular questões de gestão municipal à Política Nacional de Mobilidade Urbana. Metodologicamente, são realizados levantamentos de campo para medições e mapeamentos dos aspectos físico-espaciais; análises espaciais e de dados aerofotogramétricas com o uso de geotecnologias SIG; análise qualitativa de transporte público e integração com alternativas na microacessibilidade. Priorizam-se cenários de transporte coletivo e não motorizado, promoção da caminhabilidade e acessibilidade universal; redução do uso de veículo individual motorizado, considerando limites e desafios para assegurar a mobilidade urbana sob premissas de inclusão social e da sustentabilidade ambiental. Analisam-se ao final os resultados da inserção de projetos ciclo viários e de conexão intermodal pela gestão municipal.

Palavras-chave: Mobilidade Urbana. Microacessibilidade. Periferia. Espaços livres. São João de Meriti.

\section{Abstract}

This article investigates the urban mobility scenarios in São João de Meriti, peripheral municipality of Rio de Janeiro metropolitan region. Featuring the State's largest demographic density and one of the lowest urban well-being indexes (IBEU), the 'dormitory-city' is defined by its daily center-periphery's work force commuting. The qualitative and empirical research seeks to: identify the road networks system structure and flows in multiple urban accessibility scales; understand local urban reality, public policies and planning actions - railroad installation, demographic explosion, opening of highways

MMPC é arquiteto-urbanista e mestre em Desenvolvimento Territorial e Políticas Públicas, e-mail: mmourao.arq@gmail.com

DA é professora associada, e-mail: dalcantara@ufrrj.br 
connecting Rio and São Paulo, industrialization process; and analyze the articulation between municipal governance and the National Urban Mobility Policy. Methodologically, the investigation is carried out through field surveys for physical aspects measuring and mapping; data and spatial analysis using GIS; transit network qualitative analysis in connections with micro accessibility level alternatives. The analysis prioritizes collective and non-motorized transportation scenarios; promotion of walkability and universal accessibility; private motorized vehicles reduction, considering limits and challenges to safeguard urban mobility under the premises of social inclusion and environmental sustainability. In conclusion, we present the outcomes of the assessment of bicycle lanes and multimodal connectivity projects promoted by the municipality.

Keywords: Urban mobility. Periphery. Open spaces. Microaccessibility. São João de Meriti.

\section{Introdução}

Considerando a mobilidade fator essencial para as atividades urbanas - com poder de influenciar positiva ou negativamente indivíduos, atividades econômicas e configuração morfológica e socioespacial territorial -, esta investigação analisa a dinâmica socioespacial da mobilidade urbana no município de São João de Meriti, RJ, doravante SJM, conhecido como 'formigueiro das Américas', pela alta densidade demográfica. A esperada ordenação e hierarquização de funções e atividades com eficiência e eficácia presentes em um formigueiro não se verifica em aglomerados urbanos periféricos brasileiros, como é o caso de SJM. O desafio de solucionar problemas de mobilidade integrada, sustentável e socialmente inclusiva é então posto à prova no município, que vem buscando a melhoria de seu sistema de circulação e mobilidade, fundamental para o pleno funcionamento urbano e bem-estar social.

0 entendimento dos conceitos periferia metropolitana, mobilidade urbana e acessibilidade, bem como a análise multiescalar, norteiam a pesquisa empírica-qualitativa. 0 objeto central e recorte espacial, limitado ao município e suas conexões inter e intraurbanas no âmbito metropolitano, consideram aspectos socioeconômicos, culturais e ambientais, relevantes nas questões da mobilidade urbana e produção da cidade. A delimitação temporal inicia-se pouco antes da emancipação do município em 1949 e início da expansão demográfica na região da baixada (Abreu, 1987), contextualizando historicamente sua evolução e ocupação.

Este estudo está alinhado com a Política Nacional de Mobilidade Urbana (PNMU) (Brasil, 2012) e com os Objetivos de Desenvolvimento Sustentável (ODS) (United Nations, 2017), que têm como premissas prioridade ao pedestre, ao transporte ativo e coletivo com zero emissão de gás carbônico, além da redução do uso de automóvel particular, contrapostos às políticas públicas propostas no Plano Diretor Municipal (PDM) de SJM. Assim, são analisadas ações administrativas municipais e estaduais que promovem tais ações e seus impactos na mobilidade urbana local.

Resultado de pesquisa de mestrado e de envolvimento técnico com a gestão pública municipal, este trabalho vincula-se à pesquisa do grupo GEDUR, que investiga desigualdades e conflitos socioambientais em territórios da borda oeste metropolitana sob a perspectiva da globalização e do planejamento urbano sustentável (Alcantara et al., 2019). O arcabouço metodológico segue o desenvolvido pelo grupo e abarca e aprofunda conceitos sobre mobilidade e acessibilidade com base em Zegras (2005), Portugal (2017) e Teixeira (2006), bem como aplica instrumentos de análise socioespacial: levantamentos de campo, coleta de dados, produção cartográfica com base em SIG (Alcantara, 2020), e análise de cenários, com base em Schoemaker (1995) e Rubem et al. (2014).

0 artigo se estrutura em quatro partes. A primeira aborda a formação e mazelas da relação centro-periferia brasileira e fluminense e apresenta um panorama social, econômico e ambiental do recorte de estudo, SJM, e sua inserção na Região Metropolitana do Rio de Janeiro (RMRJ). Na segunda, aprofunda-se o quadro teórico-metodológico que fundamenta a pesquisa. A terceira parte analisa o PDM, suas intenções e lacunas; a PNMU, ressaltando a questão da mobilidade sustentável; e a política 
federal de fomento às ações municipais, Programa Avançar Cidades - Mobilidade Urbana. Na quarta, a microacessibilidade é posta à prova, na implantação de rede cicloviária interligando bairros a terminais intermodais, analisados sob a perspectiva de cenários prospectivos. As conclusões refletem os aspectos analisados e os resultados alcançados.

\section{São João de Meriti - a relação de dependência periferia-centro}

A formação social é o ponto de partida para o entendimento das dinâmicas de ocupação e padrão de urbanização na periferia metropolitana fluminense. Segundo Abreu (2010), para o entendimento da evolução de uma sociedade e sua estrutura urbana, devemos compreender a formação social que contribuiu para a produção e dinâmica de ocupação de seu espaço urbano, que incluem o padrão de moradias, produção, circulação e distribuição de bens e consumo etc. Tais processos são determinados histórica e espacialmente (Abreu, 2010). No recorte aqui proposto, resgatamos a formação da periferia metropolitana desde meados do século XX.

0 processo de urbanização fluminense foi acompanhado pelo decurso da metropolização, ou expansão e encadeamento de integração de territórios a partir de uma cidade-núcleo, resultando em um território ampliado, onde se pressupõe o compartilhamento de funções de interesse comum. 0 avanço da metropolização no Rio de Janeiro gerou, quase que simultaneamente, a periferização da Baixada Fluminense, paralelamente a um sistema urbano incipiente. Em 1940, apenas 23,6\% da população vivia em cidades. Em 2000 este percentual atingiu 81,2\% (IBGE, 2019). A urbanização da periferia não foi acompanhada por políticas e ações públicas que produzissem cidades capazes de absorver o contingente de migrantes urbanos, atraídos pelo emprego na indústria. Santos (1986, p. 2) argumentava que,

Não foi só o governo. A sociedade brasileira em peso embriagou-se, desde os tempos da abolição e da república velha, com as idealizações sobre progresso e modernização. A salvação parecia estar nas cidades, onde o futuro já havia chegado. Então era só vir para elas e desfrutar de fantasias como emprego pleno, assistência social providenciada pelo Estado, lazer, novas oportunidades para os filhos... Não aconteceu nada disso, é claro, e, aos poucos, os sonhos viraram pesadelos.

O movimento migratório campo-cidade ocorreu, entre outras razões, por conta das mudanças políticas a partir dos anos 1930: regulamentação do trabalho urbano (não extensiva ao campo) e incentivo à industrialização. Vincula-se ainda aos desequilíbrios econômicos, sociais e ambientais nas grandes cidades, principalmente São Paulo e Rio de Janeiro, atraentes pela oferta de qualidade de vida e empregos. Como consequência do aumento populacional nos centros urbanos, ampliaram-se a desigualdade social, a segregação urbana, a necessidade de moradia e os assentamentos precários, entre outras formas de exclusão social (Maricato, 2003). O processo de metropolização no Rio de Janeiro produziu 'cidades-dormitórios' (Amorim, 2016), como SJM, com alto percentual populacional se deslocando diariamente para outras centralidades (Serpa, 2013), marcado pelas carências e ausência de uma esfera pública que fomentasse o desenvolvimento socioeconômico.

Município metropolitano, SJM possui uma das maiores densidades demográficas nacionais $13.024,60 \mathrm{hab} / \mathrm{km}^{2}$. Até meados de 1940, o espaço geográfico conhecido como Grande Iguaçu, hoje Baixada Fluminense, tinha como principal atividade a citricultura. Com o processo de metropolização fluminense, a periferização da baixada se deu de forma acelerada, em uma ocupação caracterizada por loteamentos irregulares, autoconstrução, sem infraestrutura e com atuação por vezes omissa do Estado (Silva, 2017).

SJM é fortemente impactado pela conurbação urbana com Belford Roxo, Duque de Caxias, Mesquita, Nilópolis e Rio de Janeiro, configurando-se morfologicamente como um único tecido urbano, contínuo, adensado. Delimitado pelos eixos viários e rede hídrica, a Via Light o limita a sudoeste com Nilópolis; 
o Rio Sarapuí, a nordeste com Belford Roxo; e o Rio Pavuna e a Linha Vermelha, a sudeste com o Rio de Janeiro.

O adensamento construtivo ocupa praticamente todo seu território de $34,838 \mathrm{~km}^{2}$, com população estimada em 472.406 habitantes (IBGE, 2019). Mais de $90 \%$ do solo urbano é ocupado por uso habitacional, e o restante por serviços, comércios e um parque industrial. Os espaços livres de edificações, tais como vias, largos, calçadas, estacionamentos, praças, terrenos baldios, parques, etc. (Magnoli, 2006), se restringem às funções de circulação urbana, ou seja, a malha viária, e aos topos dos morros ainda não ocupados. A população de baixa renda se distribui dispersa, precária e informalmente pelo território plano, que contabiliza 36 assentamentos subnormais. As várias carências em relação à infraestrutura urbana - abastecimento, saneamento, pavimentação - e social - precário atendimento em educação e saúde - representam um dos maiores desafios para a administração municipal em relação ao planejamento urbano, implementação de políticas públicas e ações de gestão territorial (Figura 1).

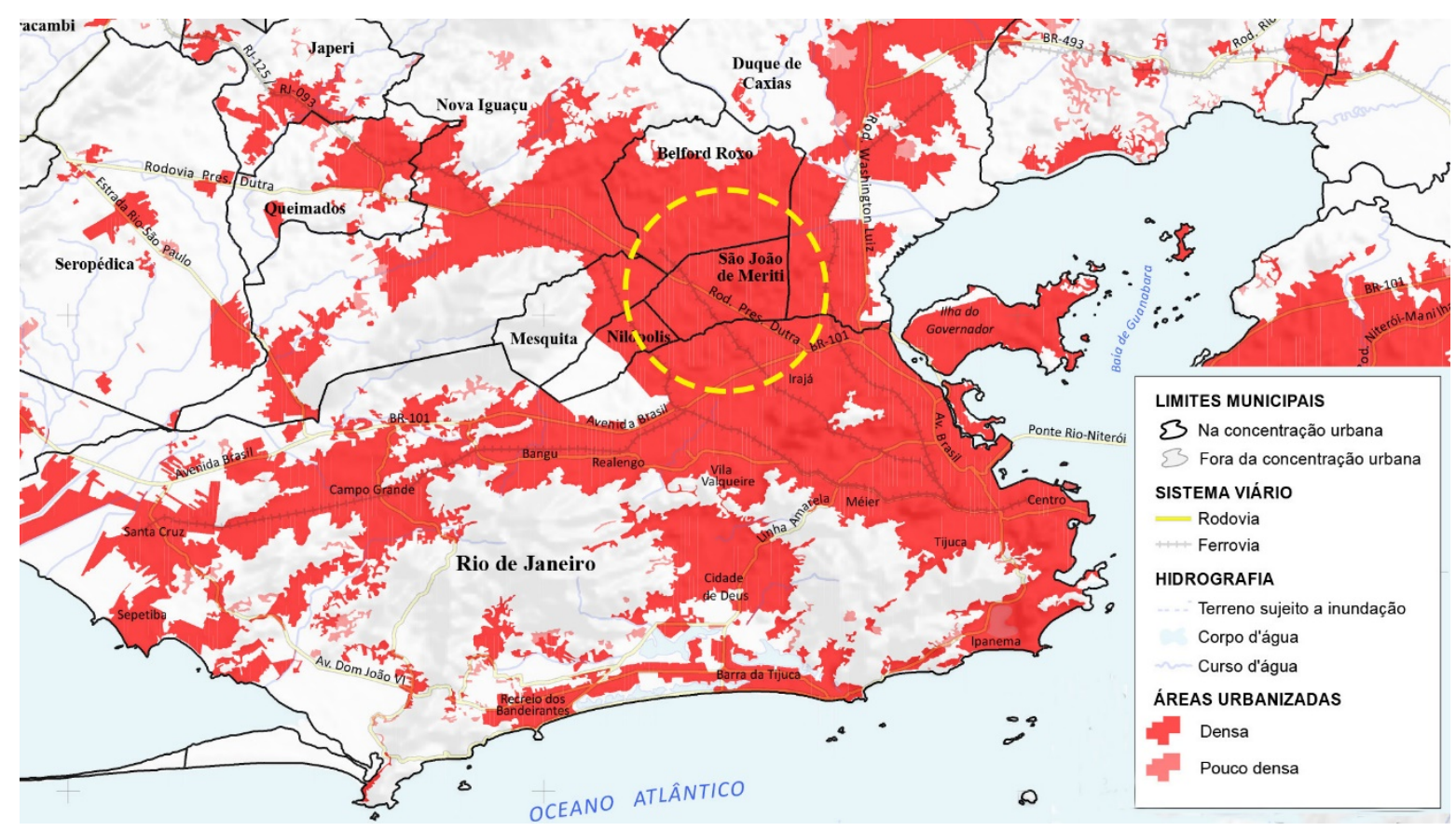

Figura 1 - Mapa de áreas urbanizadas da RMRJ com a localização de São João de Meriti. Fonte: Edição dos autores sobre mapa do IBGE, Ano: 2019 (IBGE, 2019).

Em termos sociais, nos últimos vinte anos houve aumento do IDHM ${ }^{1}$, considerado alto, 0,719, ainda que próximo ao limite inferior, entre 0,7 e 0,799 (PNUD, 2013). 0 Índice de Bem-Estar Urbano (IBEU) expande as categorias de análise, incluindo cinco dimensões urbanas - mobilidade, condições ambientais, habitação, acesso a serviços e infraestrutura - não contempladas pelo IDHM. Em SJM, o IBEU de 0,745 alcança a 3628 a colocação entre 5655 municípios brasileiros pesquisados. Na análise segmentada, o índice na dimensão mobilidade de 0,598 é um dos piores em termos nacionais, refletindo um quadro que afeta toda a RMRJ, inclusive o município do Rio de Janeiro, com apenas 0,691. Na dimensão infraestrutura urbana, SJM alcança apenas 0,665, e o Rio de Janeiro, 0,771 (Observatório das Metrópoles, 2019). Esses dados reafirmam o argumento quanto às deficiências de mobilidade e infraestrutura municipais, que geram desigualdades urbanas e sociais na metrópole (Ribeiro, 2016). Apenas a título de ilustração, dentre os 92 municípios fluminenses, SJM figura na $75^{\text {a }}$ colocação, junto com outros municípios da RMRJ com IBEU inferior².

${ }^{1}$ IDHM - Índice de Desenvolvimento Humano Municipal (PNUD, 2013).

2 IBEU menor que Meriti: Duque de Caxias (78º), Tanguá (79ํ), Nova Iguaçu (81ํ), São Gonçalo, Seropédica, Magé, Queimados (84ํㅜ a 87ํㅜ), Belford Roxo, Itaboraí, Maricá e Japeri. (Observatório das Metrópoles, 2019). 
A alta densidade construtiva tornou praticamente todo o solo urbano impermeabilizado e desprovido de cobertura vegetal, fato agravado pela rarefeita arborização viária $(30,1 \%)$ e carência de praças e espaços livres públicos destinados ao lazer. As poucas massas arbustivas estão restritas aos topos dos morros ainda não ocupados. 0 uso residencial e o caráter de autoconstrução das moradias baixas (até três pavimentos) predominam.

Os subcentros municipais ativam a economia local, porém não atendem à demanda por emprego e renda. Distribuem-se pelos bairros de Vilar dos Teles, Coelho da Rocha e São Mateus, além do Shopping Grande Rio, uma centralidade regional, e são vitais para o desenvolvimento e oferta de emprego. 0 comércio responde pela maior parte da receita, com mais de 5 mil estabelecimentos, sendo 89\% microempresas gerando 37 mil postos de trabalho ${ }^{3}$. 0 setor secundário responde por $56 \%$ do valor adicionado, principalmente no segmento de indústria alimentícia que, juntamente com as atividades informais do setor de confecções, garantem parte da oferta de emprego em SJM (TCE, 2006). 0 mapa a seguir localiza os subcentros de Tipo 1, correspondentes às áreas consolidadas com maior intensidade e diversidade de atividades de comércio e serviços; de Tipo 2, relativos a centros de menor intensidade; além da Zona Central, Zonas Industriais e Centro Administrativo, próximos aos eixos viários; localiza também aglomerados subnormais (Figura 2).

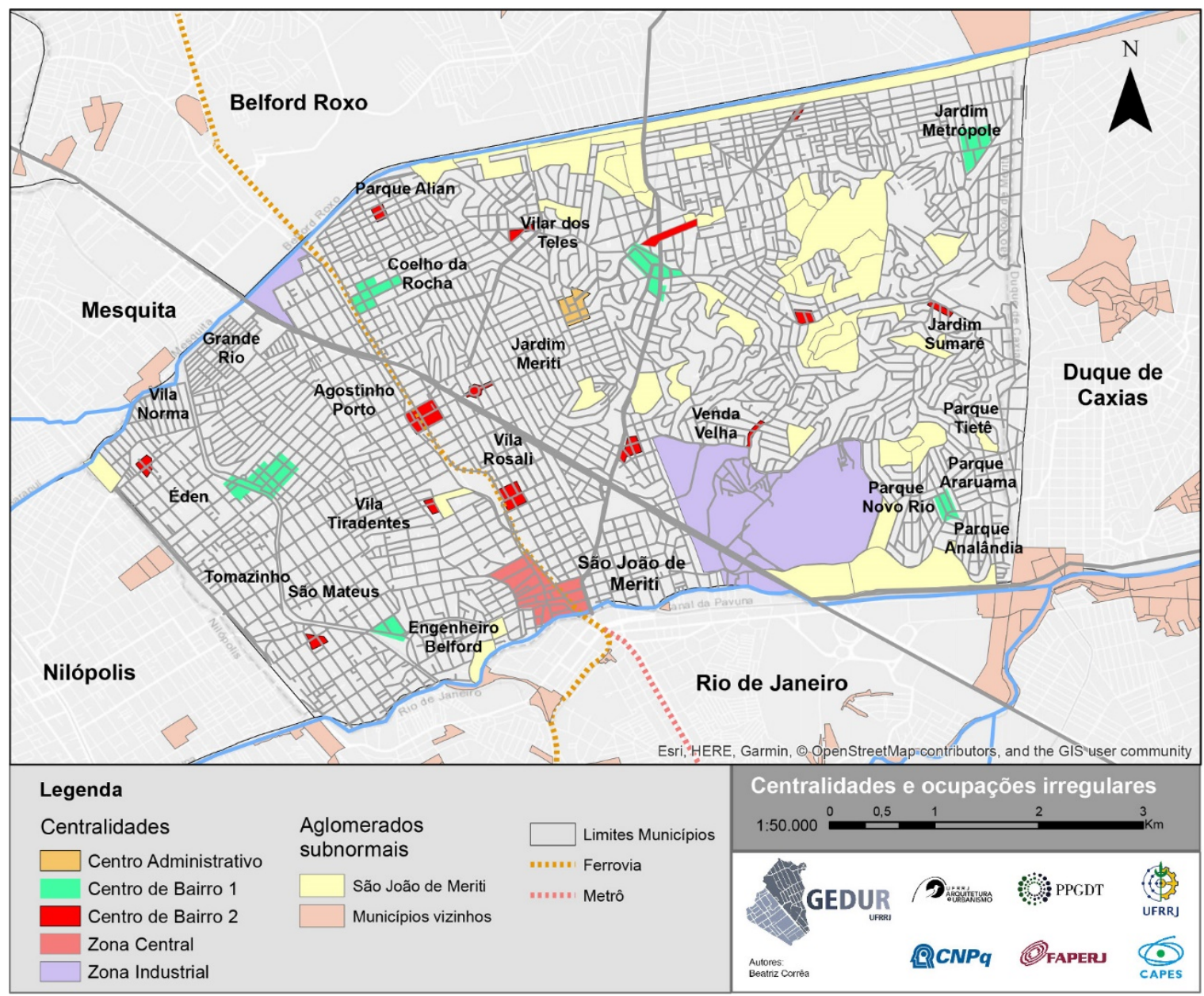

Figura 2 - Principais eixos viários e centralidades de SJM. Fonte: Acervo GEDUR.

A relação trabalho-moradia é uma questão primordial na formação do espaço urbano. As cidades se interligam e realizam trocas de informação e bens, tais intercâmbios não configurando apenas fluxos entre cidades, mas se estabelecendo em estruturas geradas pela exploração econômica e exercício do

\footnotetext{
${ }^{3}$ Cf. artigo em 0 Globo (2017) e TCE (2006).
} 
poder. A análise das dinâmicas de trocas entre as cidades e a divisão territorial do trabalho possibilita a compreensão das interações na rede de fluxos e da segregação imposta pelos deslocamentos pendulares, pois “[...] além de um recorte de classe, raça ou faixa etária, a segregação também se expressa através da separação dos locais de trabalho em relação aos locais de moradia [...]" (Rolnik, 1995, p. 42).

Em SJM a proporção de servidores públicos municipais é de $11 \%$ sobre o total de 58.166 trabalhadores formais (TCE, 2006, p. 15), ou seja, para uma população de 458.673 habitantes em 2010 (IBGE, 2019), apenas 12,6\% da população ativa ocupada (65\%) encontra-se empregada no município. Os demais $70 \%$ trabalhadores formais ou informais, 260.434 pessoas, têm que se deslocar para outros locais em busca de emprego e renda (PNUD, 2013). A maioria da população em idade ativa depende do transporte público e perde muitas horas no deslocamento pendular diário, fazendo persistir o estigma de cidade-dormitório. Trabalhadores e estudantes se deslocam por ônibus ou trens, na escala regional, porém em uma infraestrutura pouco sólida, confiável ou segura. Nessa escala macro, a Rodovia Presidente Dutra (BR116-Rio-São Paulo) configura-se um dos principais eixos, além da Via Light (RJ-0810) e Avenida Automóvel Clube (RJ-085), arteriais que interligam diversos municípios da Baixada Fluminense (Figura 3).

A ferrovia representa um dos elementos definidores da ocupação urbana da Baixada (Abreu, 1987) e tem duas estações em SJM, do ramal Belford Roxo da Supervia. Destaca-se a importância deste ramal ferroviário no deslocamento pendular diário que representa acesso ao trabalho e renda fora do município. Enfatiza-se aqui que, na relação centro-periferia, SJM atua como fornecedor de mão de obra barata e pouco qualificada.

As grandes distâncias percorridas para trabalhar somadas à precariedade do transporte público impactam a população e o cenário socioeconômico local, o que, somado ao déficit de espaços culturais e lazer, tornam o Centro metropolitano um grande ímã, pelas oportunidades profissionais, de serviço e cultura. A questão em aberto é a acessibilidade ao Centro pela população periférica, dado que os modais de transportes públicos, ônibus e trens, apesar dos investimentos recentes de ampliação e melhorias na rede, deixam a desejar especialmente em termos de confiabilidade e disponibilidade (Correa \& Gomes, 2018).

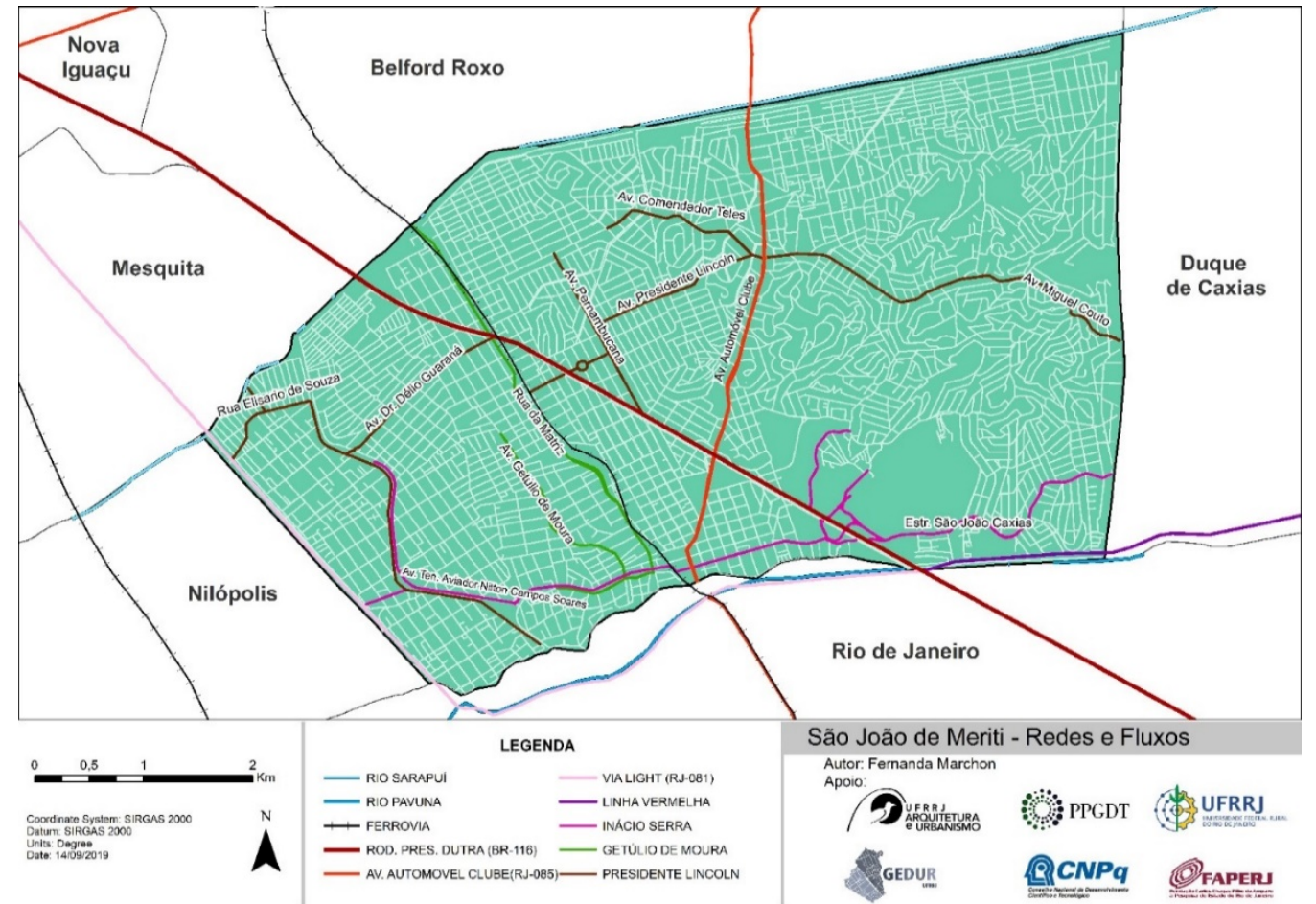

Figura 3 - Malha Viária e hidrografia de SJM. Fonte: Acervo GEDUR. 
Na escala municipal, o principal meio de transporte é o ônibus. Conforme os levantamentos realizados pela pesquisa, a rede de transporte público rodoviário conta com 70 linhas de ônibus; destas, 35 atendem a população dos municípios conurbados. As outras 35 linhas ativas percorrem os bairros meritienses, mas não atendem satisfatoriamente a todos, gerando dificuldades de mobilidade entre as localidades e os subcentros. A demanda por transporte público, tanto intra quanto intermunicipal, revela a importância de um sistema de transporte urbano eficiente, confiável e seguro, que interligue estações de trens e terminais rodoviários aos meios de circulação na escala local. A necessidade de vencer tais distâncias nos bairros mais distantes, muitos não servidos por qualquer modal de transporte público formal, obriga ao uso de transporte irregular e não confiável, como vans e mototáxis, ou bicicletas, ou, ainda, ao percurso de longas distâncias a pé, sem conforto ou infraestrutura de acessibilidade universal.

No contexto acima, é urgente repensar o planejamento e gestão de políticas públicas de mobilidade urbana, com um sistema intermodal que interligue SJM ao núcleo e outras centralidades metropolitanas, bem como entre os bairros centrais e os mais remotos, nas várias escalas, desde a regional até a local, em alinhamento às diretrizes propostas pela Nova Agenda Urbana (United Nations, 2017) e aos ODSs, cujo item 11.7 enfatiza "[...] proporcionar o acesso universal a espaços públicos seguros, inclusivos, acessíveis e verdes, em particular para as mulheres e crianças, pessoas idosas e pessoas com deficiência" (Nações Unidas, 2015, p. 30).

\section{Mobilidade urbana sustentável}

Conforme preconiza a PNMU (Brasil, 2012), a implantação de ciclovias, rotas de transporte público e melhorias na infraestrutura urbana podem ocasionar efeitos positivos no espaço urbano, promovendo segurança, apropriação e convivialidade, além de amenizar efeitos das ilhas de calor. As políticas públicas de mobilidade devem ainda assegurar o uso do transporte não motorizado, ativo e sustentável, priorizando o cicloviário e o peatonal, com acessibilidade universal, garantindo aos cidadãos meios seguros para se deslocarem no meio urbano e periurbano.

Mas não foi sempre assim. As discussões sobre mobilidade urbana, iniciadas ainda no início do século vinte, com o surgimento dos veículos motorizados, se concentrava no tráfego veicular e no espaço viário, cujo foco recaía na maior capacidade quantitativa, velocidade das viagens e incentivo ao uso do automóvel particular. Mais recentemente, essa complexa questão, ainda presente nas cidades, vem recebendo um olhar multimodal e interdisciplinar. Entende-se mobilidade como o resultado da interação entre as características individuais e as condições de acessibilidade, que, por sua vez, depende da integração entre transporte e uso do solo (Portugal, 2017). 0 transporte envolvendo infraestruturas e serviços consonantes aos usos proporciona as condições ideais de acessibilidade às atividades e oportunidades citadinas. A análise cíclica do uso do solo demonstra como as transformações configuram toda uma cadeia de eventos e podem acarretar a valorização ou desvalorização da terra (Teixeira, 2006).

Em um bom planejamento urbano, aquele em que se busca uma concepção urbana ambientalmente sustentável, socialmente inclusiva e equitativa, a acessibilidade deve ser um dos principais focos (United Nations, 2017). Nesse sentido, a Lei da Mobilidade (Brasil, 2012) representa um papel transformador para o desenvolvimento dos municípios brasileiros. A Lei define diretrizes, princípios e objetivos de planejamento sobre acessibilidade urbana incidentes sobre todos os municípios brasileiros com mais de 20 mil habitantes e norteia a elaboração de normas e procedimentos para implementação de políticas pelos municípios.

A PNMU está fundamentada nos princípios de acessibilidade universal; desenvolvimento urbano sustentável nas dimensões socioeconômicas e ambientais; equidade de acesso ao transporte público coletivo; eficiência, eficácia e efetividade na prestação dos serviços de transporte urbano e na circulação urbana; gestão democrática e controle social; segurança nos deslocamentos de pessoas; distribuição justa de benefícios e ônus de uso de modais e serviços; equidade no uso do espaço público 
de circulação. Objetiva a redução de desigualdades e promoção da inclusão social e acesso aos serviços básicos e equipamentos sociais; melhoria nas condições urbanas quanto à acessibilidade e à mobilidade; promoção do desenvolvimento sustentável e mitigação dos custos ambientais e socioeconômicos relativos aos deslocamentos urbanos de pessoas e cargas. Prevê ainda a consolidação da gestão democrática como instrumento e garantia da continuidade do aprimoramento da mobilidade urbana. Destacamos as diretrizes da PNMU, cujo alcance demanda a coerência com as demais políticas urbanas estabelecidas pelos PDMs:

- Prioridade aos modos de transportes não motorizados e serviços de transporte público coletivo;

- Integração intermodal e de serviços de transporte urbano;

- Mitigação dos custos ambientais, sociais e econômicos dos deslocamentos de pessoas e cargas;

- Incentivo ao desenvolvimento científico-tecnológico com uso de energias renováveis, menos poluentes;

- Priorização de projetos de transporte público coletivo estruturadores do território e indutores do desenvolvimento urbano integrado.

De modo a atender aos princípios e objetivos acima, o território deve ser entendido a partir de escalas distintas. Assim, as dimensões espaciais, temporais, quantitativas ou analíticas são essenciais para o dimensionamento de objetos e processos. As escalas da acessibilidade podem ser classificadas em níveis - micro, meso ou macro - de acordo com a abrangência e visibilidade do fenômeno (Gibson et al., 2000). Diferentes escalas possibilitam diferentes níveis de análise conforme recortes espaciais distintos; compreendê-las torna-se fundamental no planejamento urbano que favoreça de modo equilibrado a oferta de infraestrutura de transporte, congruente com as atividades, oportunidades e trabalho (Portugal, 2017). As escalas espaciais de acessibilidade se diferenciam pela abrangência geográfica variando de uma área menor, ou local, de vizinhança, até a mais abrangente, ou escala global, de nível estratégico, regional, sendo relativas à dimensão do espaço de intervenção (Zegras, 2005; Portugal, 2017), sendo classificadas como:

- Microacessibilidade: relativa à acessibilidade peatonal; circulação a pé ou ativa (bicicleta, patins, skate etc.), permitindo maior aproximação e sensibilidade com o ambiente construído nos percursos; distâncias até $1 \mathrm{~km}$;

- Mesoacessibilidade: inclui, além da caminhada e da bicicleta, devido a sua maior extensão, meios motorizados de transportes; escala de bairro, de região administrativa ou município periférico; distâncias até $10 \mathrm{~km}$.

- Macroacessibilidade: de maior extensão, inclui meios motorizados de transporte público; abrangência metropolitana e intermunicipal com mais de $10 \mathrm{~km}$; demanda uma rede multimodal mais complexa, qualificada e de maior capacidade.

Em quaisquer das escalas de acessibilidade, devem ser priorizadas as viagens mais curtas e rápidas, bem como estimulado o uso de transporte público e não motorizado, e desestimulado o uso de automóveis particulares. Devem ser aplicadas com a mesma diligência à infraestrutura de acessibilidade universal, favorecendo o deslocamento das pessoas portadoras de necessidades, em alinhamento com a PNMU (Brasil, 2012) e os ODS (United Nations, 2017).

\section{Planejamento urbano e Mobilidade em SJM}

A ideia de um ambiente urbano bem planejado, acessível, seguro, sustentável e funcional não é recente. Planos urbanísticos foram propostos para o Rio de Janeiro com vieses distintos, tais como o Plano Agache, o Doxíades (Andreatta, 2006), e após a Constituição de 1988, os Planos Diretores Municipais. Neles são definidas diretrizes de desenvolvimento urbano e o fortalecimento econômico, 
para valorizar potencialidades locais e regionais, conservar os recursos naturais, o pleno desenvolvimento das funções sociais da cidade e melhorar a qualidade de vida e o bem-estar dos cidadãos. De acordo com Maricato (2003), não é por falta de planos urbanísticos que as cidades brasileiras apresentam problemas de desordenamento urbano, nem devido à má qualidade destes. 0 crescimento das cidades e a distribuição das benfeitorias são direcionados a interesses políticos locais e a grupos específicos que, ao apoiar e/ou subsidiar determinada ação, exigem privilégios e facilidades em prol de seus interesses particulares, sem priorizar o interesse coletivo. A expansão metropolitana pode ser entendida a partir dessa assertiva.

Quando o planejamento urbano é usado como instrumento de dominação ideológica, oculta-se a cidade real e passa a dominar o mercado imobiliário especulativo (Maricato, 2001). 0 desenvolvimento de bairros, distritos e municípios se torna uma fonte inesgotável ao tradicional clientelismo político: é moeda de troca de votos por melhorias infraestruturais (Maricato, 2003). Assim, a urbe não se conecta por inteira, tornando o direito à cidade restrito à elite política e econômica que concentra os mecanismos de moldá-la conforme seus interesses (Harvey, 2014). "O direito à cidade é [...] muito mais do que um direito de acesso individual ou grupal aos recursos que a cidade incorpora: é um direito de mudar e reinventar a cidade mais de acordo com nossos mais profundos desejos." (Harvey, 2014, p. 28).

Planos diretores municipais incluem diretrizes de acessibilidade e mobilidade urbana, entretanto as políticas nem sempre são postas em prática na forma da lei. Ao analisamos o Plano Diretor Municipal de SJM (PDM) sob a ótica da mobilidade, verifica-se que estabelece nos artigos 35 e 36 uma única macrozona urbana abrangendo todo o território, subdividindo-se em: zona urbana e zona urbana consolidada, cuja diferença é a infraestrutura instalada, ou seja, a segunda considera, além da via aberta, iluminação pública, pavimentação e rede de telefonia (São João de Meriti, 2006). Os artigos 15 e 16 indicam a necessidade de tornar os espaços urbanos mais acessíveis e mais bem articulados fisicamente com as demais parcelas territoriais, sejam municipais ou metropolitanas. 0 macrozoneamento foi claramente definido em função da ocupação já existente no território, ou seja, sem uma visão de longo prazo quanto ao planejamento de usos ou de mobilidade, em que os principais eixos viários existentes - a Rodovia Presidente Dutra e a Via Light - configuram-se como elementos fragmentadores do tecido urbano. Outros artigos do PDM de SJM destacam a questão relativa à microacessibilidade, como o 25, que estabelece que a política deverá privilegiar: integração viária intra e intermunicipal para maior permeabilidade urbana; hierarquização e funcionalidade viária; prioridade ao pedestre, tratamento geométrico de passeios e garantia da acessibilidade universal; implementação de ciclovias; estímulo e democratização do transporte coletivo; e iluminação pública e sinalização viária para maior segurança. 0 artigo 32 é claro ao estabelecer, sobre transporte público, a implantação de novas linhas para bairros não atendidos, inclusive circulando à noite, e a regularização do transporte alternativo, como vans e mototáxis. 0 mapa abaixo (Figura 4) indica a definição do zoneamento de SJM a partir do PDM, que representa uma leitura do espaço territorial destacando as áreas de especial interesse (urbanístico, social, comercial, ambiental), os Centros de Bairro e elementos de desenvolvimento metropolitano. 


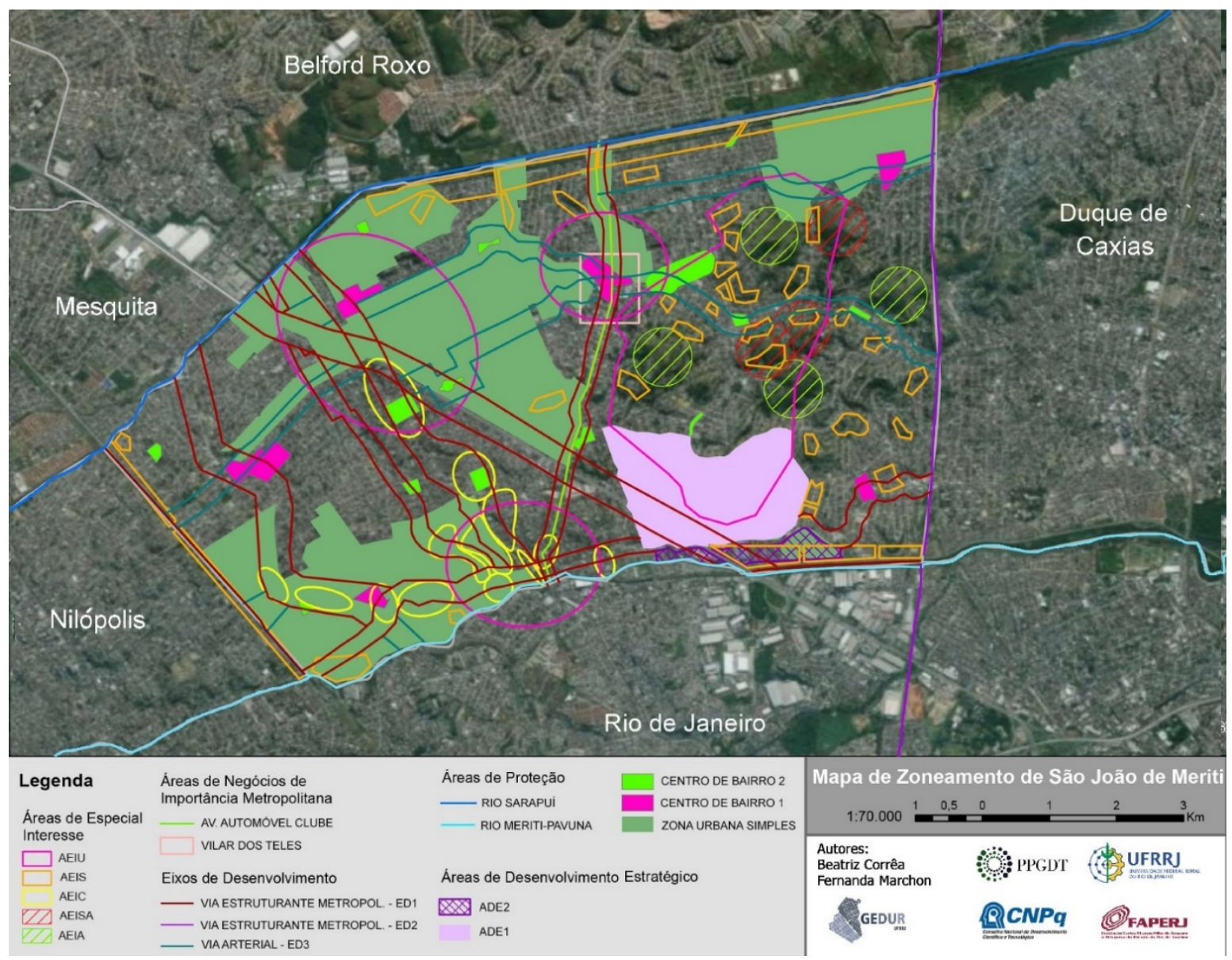

Figura 4 - Mapa de macrozoneamento de SJM, com as propostas estratégicas previstas no PDM. Fonte: Acervo GEDUR.

O plano pode ser considerado abrangente com argumentos sólidos, inclusive fazendo a relação entre a questão da mobilidade e uso do solo, como, por exemplo, com indicação de alargamento de vias e uso de faixas de domínio de rodovias e ferrovias para melhor integração com o tecido intraurbano; saneamento, drenagem e pavimentação de vias, entre outros. 0 caráter otimista do PDM deixa, entretanto, a desejar, dado que o detalhamento na forma da lei de muitas das propostas não tenha saído do papel, ficando apenas a intenção.

Essa realidade começa a ser transformada após o estabelecimento em nível nacional da PNMU, em 2012, e da mudança de gestão municipal, em 2017. 0 comprometimento dos governos e da sociedade para a implementação da PNMU é fator fundamental para a redução das desigualdades sociais a partir da melhoria das condições urbanas de acessibilidade e mobilidade, e consequentemente de oferta de acesso aos serviços e equipamentos sociais disponíveis.

A prefeitura de SJM, para fomentar os pressupostos do PDM e do PNMU, encaminhou proposta ao Programa Avançar Cidades - Mobilidade Urbana (PAC-MU) ${ }^{4}$, que financia propostas com a finalidade de proporcionar o acesso universal à cidade, de forma segura, socialmente inclusiva e sustentável. O Programa disponibiliza recursos federais do FGTS para melhorias na pavimentação de vias, acessibilidade dos passeios, sinalização e iluminação viária; implantação de abrigos de ônibus, ciclovias e ciclofaixas; e drenagem e arborização aliados a projetos de paisagismo; e construção de pontes com calçadas acessíveis (Brasil, 2018b).

Comparando o PDM com o estabelecido na PNMU, é possível perceber que no primeiro estão claras as diretrizes a serem seguidas para garantir aos cidadãos o pleno direito de ir e vir. Ambos os

\footnotetext{
${ }^{4}$ Criado em 2017 pelo extinto Ministério das Cidades.
} 
instrumentos que norteiam a política de mobilidade e acessibilidade na esfera municipal se configuram essenciais para o processo de transformação e desenvolvimento urbano e territorial. Nesse contexto ganha importância a efetivação do PDM através de legislação específica e a implementação das ações de mobilidade. Além disso, acreditando na "impossibilidade de tornar o ambiente construído independente da sociedade que constrói e ocupa" (Maricato, 2001, p. 50), reiteramos que a participação democrática e o controle social são fundamentais no pensar a cidade. Para tanto, "[...] a proposta deve ser operacionalizada e isso implica em ação e enfrentamento de conflitos [...]" (Maricato, 2001, p. 74).

Reitera-se que a prerrogativa de conceber a cidade e planejar a mobilidade não deve ser exclusividade do governo, pois todos aqueles que influenciam e interagem com a realidade local devem contribuir para seu desenvolvimento. Tanto o planejamento da mobilidade urbana sustentável quanto sua gestão devem ser efetivados por processos participativos em torno de propostas representativas da sociedade, viabilizando as alternativas econômicas existentes, aliadas à inclusão social, à acessibilidade e ao ambiente.

Coube então a investigação quanto à relação entre as diretrizes apontadas pelos planos e políticas públicas e a atuação do poder municipal de SJM em programar ações que garantam a mobilidade aliada à sustentabilidade e acessibilidade como elementos definidores da qualidade de vida urbana e que contribuam para sua democratização.

\section{Microacessibilidade posta à prova}

No processo de metropolização da RMRJ, SJM tornou-se um município onde a precariedade no ordenamento urbano e territorial é visível em todos os seus dezesseis bairros, dos mais centrais aos mais remotos. Tais problemas e deficiências acometem outros municípios da RMRJ. Em SJM, o principal problema, o alto adensamento construtivo sem infraestrutura urbana adequada, compromete sobremaneira a mobilidade e o acesso aos bens e serviços no município e em seu entorno. 0 tecido urbano é marcado pela fragmentação ocasionada pelos eixos arteriais que o atravessam, rompendo fluxos intraurbanos e ocasionando distinções socioespaciais, como ratificado pelo próprio PDM: "[...] a cidade é partida traumaticamente em três, pela Via Dutra e pela Estrada de Ferro Central do Brasil, constituindo-se em sérias barreiras à vida econômica e funcional da mesma e ainda formando verdadeiras ilhas urbanas [...]" (São João de Meriti, 2006, p. 4).

o parcelamento extensivo de quadras e lotes compete com os poucos espaços livres públicos disponíveis para outras atividades ou funções, além da circulação. Raras praças ou largos que deveriam ser destinados ao lazer ou esportes apresentam-se abandonados, subutilizados ou ocupados irregularmente. Muitas vias públicas não têm pavimentação adequada, sendo a taxa de urbanização ou zona urbana consolidada de apenas $46,9 \%$ (IBGE, 2019). As vias, mesmo quando pavimentadas, não necessariamente dispõem de drenagem pluvial, iluminação pública, sinalização ou passeios, que dirá acessibilidade universal, correspondendo aos $53,1 \%$ definidos como zona urbana simples no PDM.

Ambientalmente, a baixa taxa de arborização viária $(30,1 \%)$, a inexistência de unidades de conservação ou parques públicos e a alta densidade construtiva geram ilhas de calor e impactam o microclima urbano com baixa qualidade ambiental e de conforto térmico. 0 município possui um dos piores índices de qualidade do ar da RMRJ, onde os níveis de partículas em suspensão e inaláveis estão acima do padrão por conta do tráfego intenso de veículos em áreas mais centrais e próximas às rodovias. As ruas de terra batida, em conjunto com a prática comum de queima de lixo, contribuem para a piora da qualidade do ar, principalmente no inverno com menor precipitação e carreamento das partículas suspensas (Gregório \& Brandão, 2010).

Dentre as principais causas das enchentes e alagamentos sazonais, a expansão urbana desordenada e sem infraestrutura adequada compromete a sustentabilidade hídrica, aliando-se a baixa altitude próxima ao nível do mar e o assoreamento dos rios, que configuram a sub-bacia hidrográfica que 
deságua na Baía de Guanabara. Além disso, a precariedade do saneamento básico (100\% do esgoto coletado é lançado in natura nos corpos hídricos) acomete a população com doenças endêmicas ${ }^{5}$. Desnecessário mencionar que os impactos e inconveniências causados à mobilidade urbana são inúmeros e recorrentes, principalmente nas áreas que concentram as maiores carências socioeconômicas, que foram mapeadas nos percursos e visitas realizados em bairros próximos ou mais distantes das áreas centrais de SJM (Figuras 5 e 6).

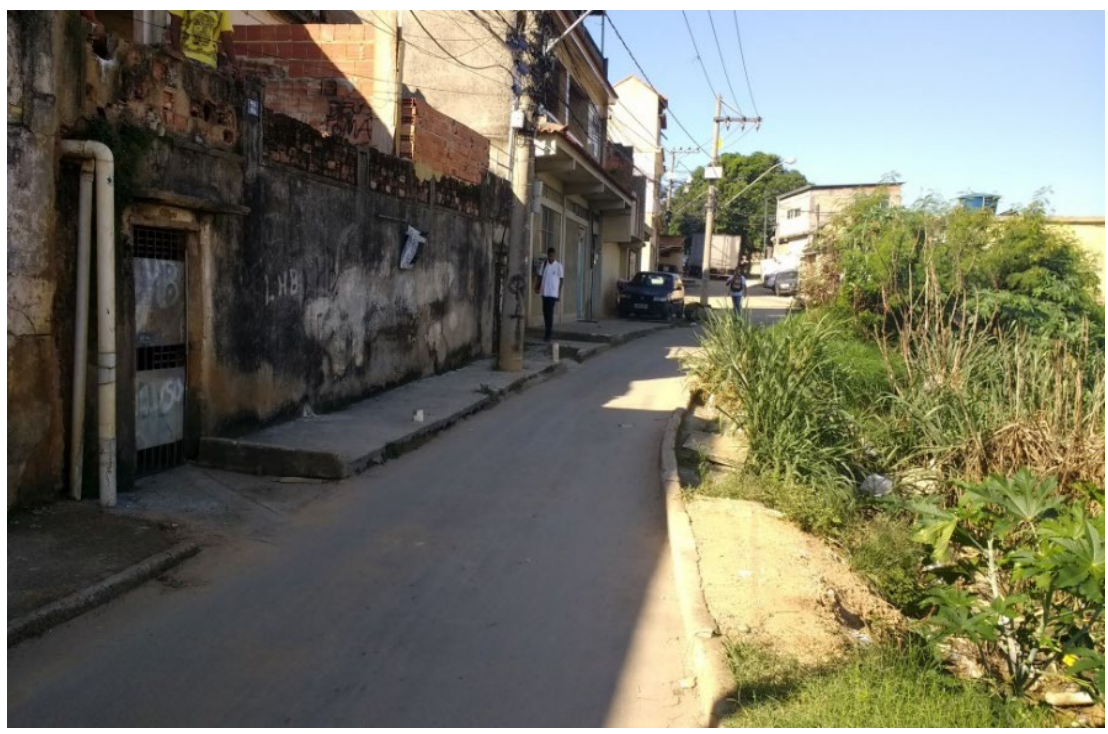

Figura 5 - Desníveis e falta de pavimentação dos passeios em rua no Bairro Jardim Meriti, próximo ao entroncamento entre a Via Dutra e a Av. Automóvel Clube. Fonte: Acervo dos autores, 2018.

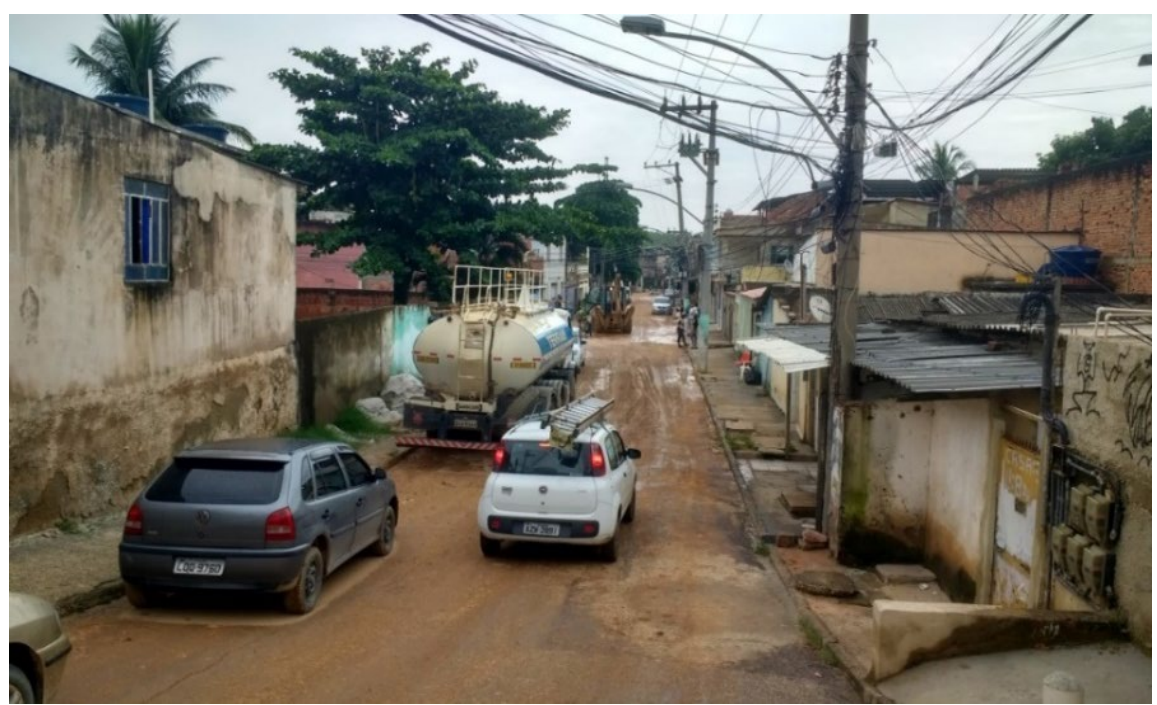

Figura 6 - Rua sem drenagem superficial no Bairro Venda Velha, com desníveis, barreiras, ocupação irregular e postes nos passeios. Fonte: Acervo dos autores, 2018.

As propostas elaboradas pela prefeitura de SJM, quanto às políticas e ações de mobilidade urbana nas escalas da meso e da microacessibilidade foram investigadas ao longo de sua implementação, considerando-se as diretrizes da PNMU. A metodologia de análise utilizada foi a de cenários prospectivos, que possibilita definir o caminho escolhido por uma organização, seja pública ou privada, para elevar o grau de interações com os ambientes interno e externo (Santos, 2013). Ao poder público cabe planejar e promover a realização de políticas que atendam às necessidades da população em um

\footnotetext{
${ }^{5}$ De acordo com o Programa Municipal de Saneamento Básico de São João de Meriti (2019).
} 
intervalo de tempo razoável e por meios factíveis, ainda que em um futuro incerto. Segundo Reyes (2015), o projeto por cenários permite discussões mais amplas, com diferentes atores e incluindo diversas comunidades em um processo mais aberto. Reiteramos, assim, a importância da inclusão social no processo.

Durante décadas, o poder municipal meritiense não atentou às questões relacionadas ao desenvolvimento e aprimoramento da infraestrutura urbana de mobilidade e acessibilidade. Com a promulgação da PNMU e suas diretrizes e obrigações a serem cumpridas pela governança pública municipal, os órgãos fiscalizadores responsáveis pelo empenho dos recursos do PAC-UM passaram a exigir seu cumprimento para aprovação dos projetos encaminhados.

Desde 2017, a gestão municipal vem realizando ações para possibilitar a implementação de projetos urbanísticos. Um de seus primeiros atos foi o resgate das audiências públicas, a fim de promover e estimular uma maior participação dos cidadãos no planejamento das políticas públicas. A primeira, realizada ainda em 2017, contou com representantes da sociedade civil, membros da defesa civil, secretários municipais e prefeito. Na ocasião, a ineficiência do sistema de saúde e a coleta de lixo foram apontados, bem como a precariedade do sistema de transportes e ineficiência da acessibilidade local. A partir daí, a gestão municipal passou a desenvolver propostas de mobilidade e acessibilidade, na escala da microacessibilidade e mesoacessibilidade, cujos cenários prospectivos são analisados a partir de sua efetivação.

\section{Mobilidade ativa - ciclovia como experimento}

Um dos projetos desenvolvidos pela Secretaria de Captação de Recursos, Urbanismo e Habitação (SECAREUH) foi a criação de ciclovia do bairro São Mateus, com extensão de 976,84 metros, abrangendo uma área urbanizada de $6.011,93 \mathrm{~m}^{2}$. 0 principal objetivo foi a ligação do bairro ao terminal rodoviário no Centro de SJM. A proposta levou em consideração a demanda pelo transporte ativo cicloviário, principal forma de deslocamento da população em áreas mal atendidas por transporte público. A ciclovia passou a oferecer um deslocamento seguro e confortável, em faixa segregada e pavimentada, arborização, paisagismo e mobiliário urbano.

0 trajeto iniciado no bairro de São Mateus foi ampliado para implantação de ciclovias no bairro Engenheiro Belford e no bairro Tomazinho, na parte sul do município. 0 primeiro trecho tem extensão de 523 metros e uma área urbanizada de $7.716,87 \mathrm{~m}^{2}$, e o segundo, com 1.183 metros e área urbanizada de $9.125 \mathrm{~m}^{2}$.

As três ciclovias atendem a bairros próximos ao Centro e aos principais eixos viários, fazendo a interligação entre modais de transporte na escala da macroacessibilidade, entre a Dutra (BR-116), a Via Light e a Av. Automóvel Clube, além de conectar a estação Pavuna-São João de Meriti, da Supervia, e a estação terminal do Metrô, na Pavuna. Sua implantação, ainda que atenda apenas a uma pequena parcela do município altamente adensado, demonstra a viabilidade e importância desse modal de transporte ativo na escala da microacessibilidade em conjunção com modais de transporte na meso e macroacessibilidade. Cerca de um ano após implantada, observações iniciais realizadas pelos pesquisadores indicam a apreciação dos habitantes pela nova infraestrutura urbana e o progressivo aumento de uso da ciclovia na ligação com outros modais. Dados mais precisos sobre a utilização da ciclovia ainda estão sendo coletados quantitativamente, mas qualitativamente a infraestrutura cicloviária demonstra sua validade na melhoria do espaço urbano, da qualidade ambiental e segurança (Figura 7). 

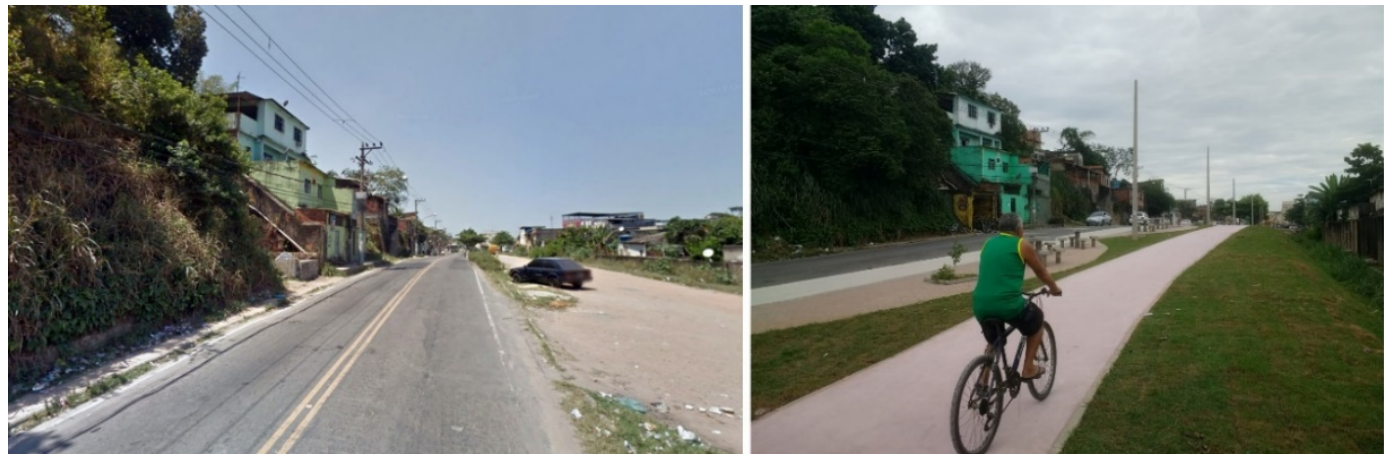

Figura 7 - Rua Dep. Rubens Paiva, Bairro São Mateus, antes (2014) e depois (2018) da implantação da ciclovia. Fontes: Google Street View e acervo autores.

Dando continuidade às ações voltadas à melhoria da infraestrutura de transportes, a SECAREUH enviou proposta ao PAC-MU, para melhoria da qualidade da prestação dos serviços de transporte público coletivo e com o intuito de promover a revitalização urbana, seguindo as diretrizes da PNMU com foco na mesoacessibilidade. 0 projeto prevê o aumento na oferta de transporte e redução de tempo e viagem; maior eficiência operacional e integração dos modais de transporte (ciclovia, ônibus e metrô); maior segurança com sinalização e iluminação; arborização de vias e a requalificação urbana em Vilar dos Teles; reforma de rodoviárias estratégicas para o transporte coletivo; expansão da rede cicloviária no bairro de Éden; e construção de passarela para pedestres sobre a ferrovia defronte à Rodoviária do Rodo. Em maio de 2019, a proposta encaminhada pela prefeitura recebeu o status de 'enquadrada' e aguarda análise pelo agente financeiro e aprovação final para contratação de empresa especializada para a elaboração do Plano Municipal de Mobilidade Urbana e minuta de projeto de lei ${ }^{6}$ (Figura 8).

As ações iniciadas pela gestão municipal, com a primeira ciclovia implantada e sua continuidade com as propostas acima, demonstram a preocupação com a melhoria da mobilidade urbana de SJM. O cenário previsto em médio prazo é positivo no sentido da inclusão das demandas da sociedade civil e da abertura de um espaço democrático para se pensar o futuro. A integração dos modais nas três escalas da acessibilidade e a reurbanização e infraestrutura previstas poderão ser benéficas ao bem-estar e à saúde da população.

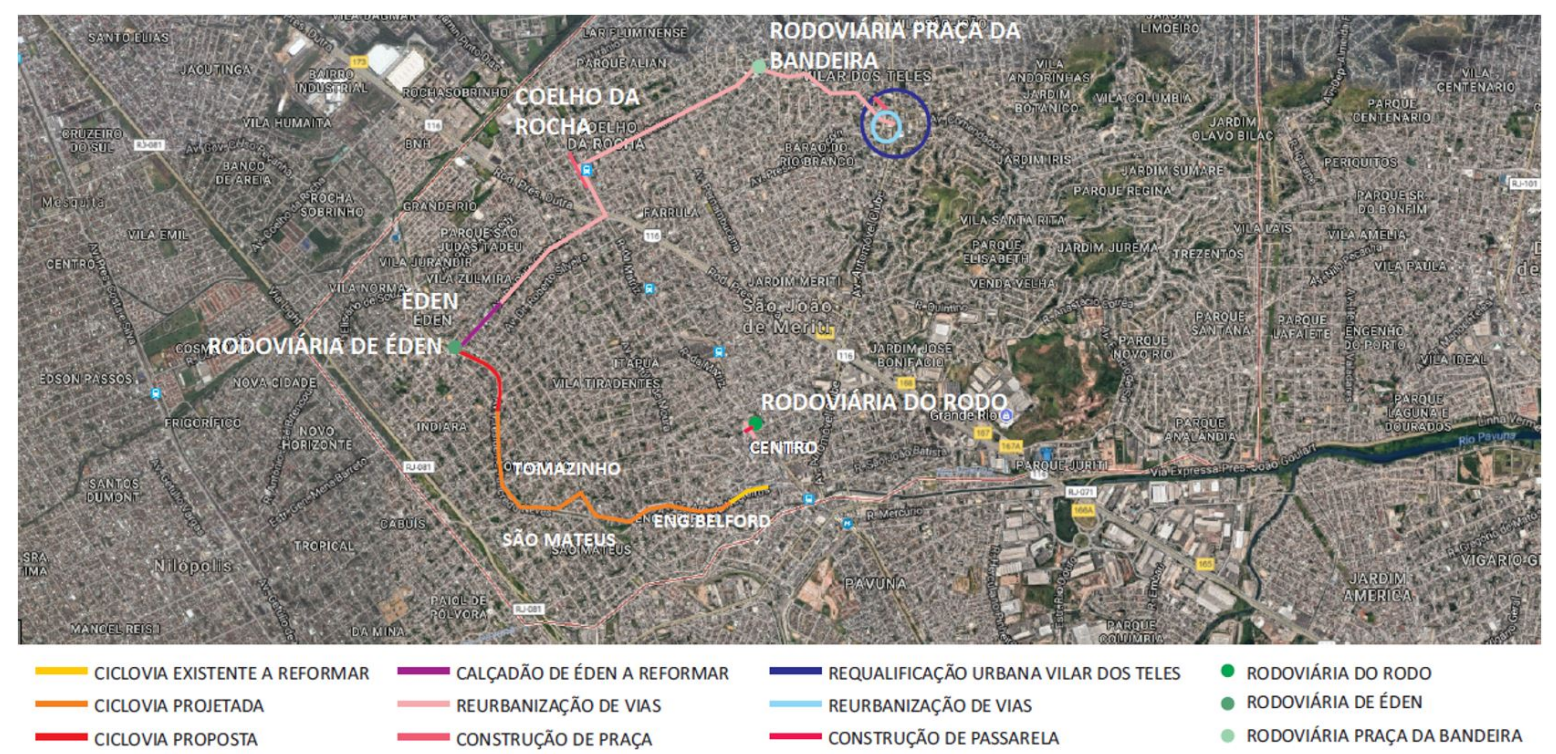

Figura 8 - Mapa com propostas de mobilidade cicloviária encaminhadas ao Programa Avançar Cidades. Fonte: SECAREUH.

\footnotetext{
${ }^{6}$ Listagem das cartas-propostas do Grupo 2 (municípios com mais do que 250 mil habitantes) disponível em Brasil (2018a).
} 


\section{Reabilitação urbana em Vilar dos Teles}

O projeto de reabilitação urbana de Vilar dos Teles configura outra ação municipal recente, para além do Centro de SJM beneficiado com a ciclovia. No bairro se observa alto fluxo de pessoas e veículos, visto que ali se localiza grande parte do comércio e serviços. Após análise realizada em campo e junto à prefeitura, foram identificados seis eixos de ação prioritários para que haja efetividade na melhoria da acessibilidade e mobilidade no bairro: drenagem, mobilidade, acessibilidade, economia, urbanização e pavimentação. A partir desses eixos, a prefeitura elaborou um projeto de reabilitação urbana para o centro comercial, seguindo as diretrizes da PNMU, objetivando amenizar os problemas identificados e melhorar a mobilidade local, beneficiando pedestres, motoristas, o comércio e a economia local, realizando intervenções urbanas de infraestrutura, mobilidade e acessibilidade universal.

Um dos maiores problemas é a drenagem pluvial, insuficiente ou inexistente, impedindo ou dificultando o escoamento da água das chuvas e, consequentemente, causando enchentes e alagamentos. Tais inconvenientes prejudicam a mobilidade e, consequentemente, a economia local, e a falta de drenagem e de boas condições infraestruturais ocasiona constantes engarrafamentos, gerando deslocamento ineficiente e grande desconforto para a população. Assim, a proposta contempla a implantação de infraestrutura de drenagem, com bocas de lobo junto aos meios-fios; redimensionamento de galerias de águas pluviais; pavimentação de vias (Figura 9).

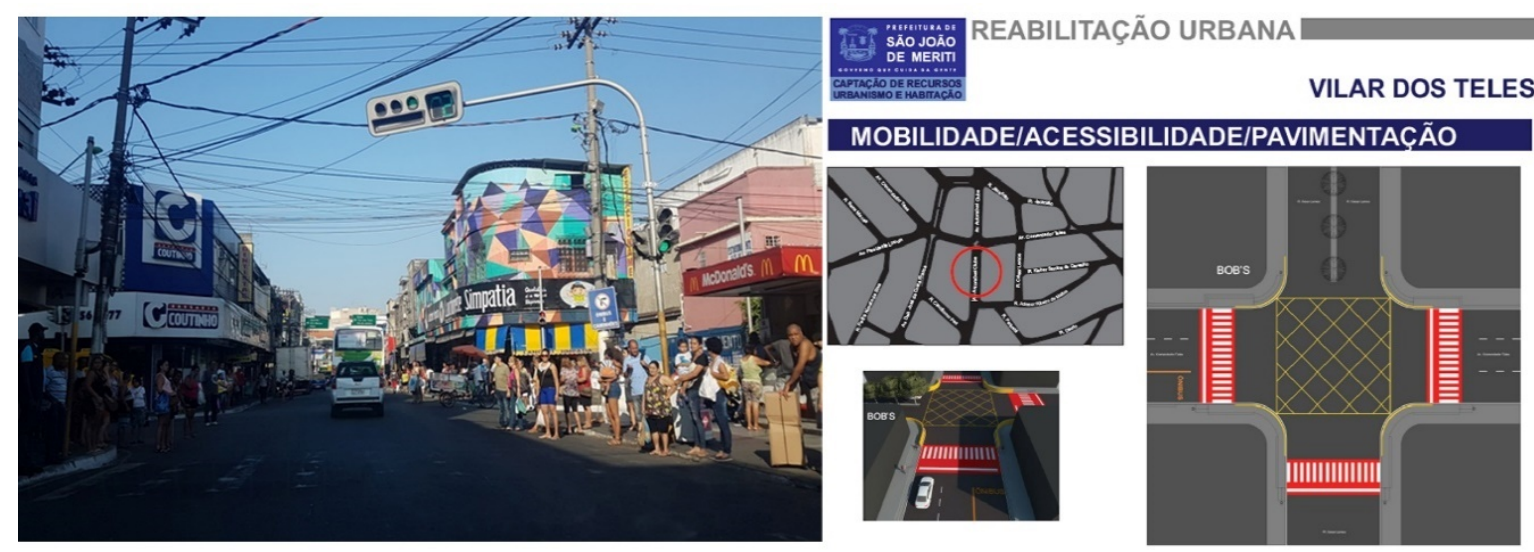

Figura 9 - Situação atual e cenário proposto para Vilar dos Teles, onde o pedestre tem prioridade. Fonte: acervo próprio (2018) e SECAREUH.

De acordo com o PNMU, a acessibilidade universal - ou seja, o acesso aos lugares, às atividades, serviços e equipamentos urbanos - é direito de todo cidadão e uma das prioridades da política pública. A pesquisa identificou que o município não apresenta condições adequadas para atender de modo inclusivo a totalidade da população, com cerca de 3\% com algum tipo de deficiência ou necessidade locomotora permanente (IBGE, 2019), excluídos daí usuários com mobilidade comprometida temporariamente (idosos, grávidas, pessoas acidentadas etc.). 0 centro de Vilar dos Teles carece de sinalização ou elementos de acessibilidade, tais como piso podotátil/alerta, rampas, entre outros elementos de desenho urbano para a acessibilidade universal. Pelo contrário, sobram obstáculos e barreiras físicas que dificultam a mobilidade. A presença de ambulantes e vendedores de rua é muito forte naquele polo comercial, competindo com o comércio formal e impactando a paisagem e a mobilidade urbana, pela ocupação irregular de calçadas e vias, estacionamento irregular, lixo etc.

As propostas acima analisadas priorizam as melhorias para as zonas centrais, estratégicas para o desenvolvimento do município, e concentram a atenção e os investimentos iniciais no que tange à melhoria do espaço urbano imediato àquelas centralidades, mas ainda não abrangendo áreas mais remotas. Para além da escala da microacessibilidade, outras propostas da SECAREUH são apresentadas brevemente. 


\section{Alteração de fluxo viário entre São João de Meriti e Pavuna}

O projeto de alteração viária abrange a escala metropolitana, consistindo em parceria entre as prefeituras de SJM e do Rio de Janeiro. A proposta de alteração de sentido de fluxo viário em vias comuns aos municípios resultará em fluxo mais dinâmico e melhor mobilidade regional. As propostas de intervenção incidem na Av. Automóvel Clube e Rua Maranhão, com novo sentido de fluxo, faixa exclusiva e abrigos para ônibus, sinalização horizontal, semáforos eletrônicos, entre outras melhorias de infraestrutura urbana. A circulação segregada de coletivos em faixa exclusiva busca maior eficiência e menor tempo percorrido.

Ainda que limitadas ao transporte público, viabilizando uma maior integração entre modais, e maior agilidade no deslocamento intermunicipal, os benefícios com a implementação das intervenções, na meso e macroacessibilidade, atingem a maioria da população dependente do transporte público para acesso a serviços, emprego e educação. As etapas de instalação de infraestrutura de drenagem e saneamento devem ser implementadas nesses percursos.

\section{Conclusões}

Este artigo buscou analisar a questão da mobilidade urbana no município de SJM, contextualizando a situação de deslocamento e circulação viária e apresentando cenários prospectivos a partir das propostas da atual gestão municipal, consolidadas a partir da criação da SECAREUH. A análise histórica destacou a carência de políticas públicas de mobilidade em nível metropolitano e municipal, que ocasionou uma urbanização fragmentada, descontínua, não inclusiva e insegura, afetada ainda por congestionamentos, alagamentos, riscos etc. Podemos considerar que esse é o resultado de um planejamento que reforça a condição periférica dos municípios metropolitanos em relação ao centro, tanto em termos de investimentos e benefícios para o segundo, quanto em dependência econômica dos primeiros. As análises do PDM de SJM, contraposto à PNMU, revelam-se políticas essenciais, porém desconsideradas por longos anos, sem definição de arcabouço legal para transformar intenções em ações efetivas, na forma da lei.

Os projetos desenvolvidos pela SECAREUH de SJM, criada em 2017, passam a alavancar nova abordagem da governança municipal, com ações voltadas à mobilidade urbana sustentável. A gestão municipal vem ampliando seu aparato tecnológico e corpo técnico na busca de soluções efetivas para tantos e tão profundos problemas existentes e identificados, não limitados às questões de mobilidade e acessibilidade. As análises de cenários sobre o processo de implementação das políticas de mobilidade urbana indicam efeitos benéficos e limitações dessas ações que poderão beneficiar os habitantes. As primeiras realizações favorecem maior qualidade e segurança no deslocamento na escala da microacessibilidade para uma parcela da população, com a implantação da ciclovia integrando bairros às estações intermodais.

A extensão da rede cicloviária, seja por faixa segregada, seja por ciclofaixa sobre a via, atendendo a bairros mais remotos, não apenas promoverá, como poderá estimular e ampliar o uso do transporte ativo com maior segurança e conforto. A urbanização e infraestrutura viária vinculadas às ciclovias promoverá a criação de corredores verdes no município com baixíssimo índice de arborização urbana, promovendo a conexão entre centralidades e estimulando a apropriação e convivialidade. As vias poderão, assim, cumprir sua importante função social, ambiental e estética, favorecendo os microclimas locais.

Verifica-se a necessidade do aprofundamento de estudos referentes aos impactos na mobilidade causados por uma urbanização definida pelo crescimento urbano explosivo de outrora, que preconizava o privilégio de investimentos às áreas destinadas às elites econômicas, em prejuízo da população pobre, empurrada para a Baixada com todas as suas mazelas. Os custos financeiros para a efetivação das propostas não foram aqui considerados, porém o retorno em qualidade de vida, efeitos 
benéficos para o ambiente e para a saúde da população e para a qualidade urbana são avaliados qualitativamente como positivos.

Finalmente, torna-se clara a demanda por mais pesquisas e estudos criteriosos e abrangentes, não somente relativos a SJM, mas a outros municípios periféricos, cujas demandas são tão similares quanto urgentes de solução.

\section{Agradecimentos}

0 presente trabalho foi realizado com apoio da Coordenação de Aperfeiçoamento de Pessoal de Nível Superior - Brasil (Capes), Código de Financiamento 001; financiado com Bolsa JCNE FAPERJ (Proc. No. E-26/202.706/2018), e concessão de bolsas de Iniciação Científica pelo CNPq e FAPERJ para graduandas que participaram ativamente da pesquisa e na confecção de mapas, às quais agradecemos nomeadamente: Fernanda Marchon de Souza da Silva e Beatriz de Medeiros Correa.

\section{Referências}

Abreu, M. (1987). Evolução Urbana do Rio de Janeiro. Rio de Janeiro: IPLANRIO/Zahar.

Abreu, M. (2010). Geografia Histórica do Rio de Janeiro - 1502-1700. Rio de Janeiro: IPP/Editora Andrea Jacobsen.

Alcantara, D. (2020). Estratégias e processos participativos para o desenvolvimento local e regional na Baixada de Sepetiba, RJ. Cadernos Metrópole, 22(47), 147-171.

Alcantara, D., Silva, M. R., \& Oliveira, N. (2019). A Periferia da Pobreza na Borda Oeste Metropolitana do Rio de Janeiro: ocupação, apropriação e (des)estruturação sócioespacial e territorial. In Anais do XVIII ENANPUR. Natal: UFRN.

Amorim, T. (2016). Cidade-dormitório. Revista Berro. Recuperado em 24 de julho de 2018, de http://revistaberro.com/literatura/cronicas/cidade-dormitorio/

Andreatta, V. (2006). Cidades Quadradas, Paraísos Circulares: Os Planos Urbanísticos do Rio De Janeiro no Século $X I X$. Rio de Janeiro: Mauad.

Brasil. (2012, 4 de janeiro). Lei 12.587, de 03 de Janeiro de 2012. Institui as diretrizes da Política Nacional de Mobilidade Urbana; revoga dispositivos dos Decretos-Leis no ${ }^{\circ}$ 3.326, de 3 de junho de 1941, e 5.405, de 13 de abril de 1943, da Consolidação das Leis do Trabalho (CLT), aprovada pelo Decreto-Lei $n^{\circ}$ 5.452, de 1o de maio de 1943, e das Leis $n{ }^{\circ}$ S 5.917, de 10 de setembro de 1973, e 6.261, de 14 de novembro de 1975; e dá outras providências. Brasília: Diário Oficial. Recuperado em 10 de julho de 2019, de http://www.planalto.gov.br/ccivil_03/_ato20112014/2012/lei/l12587.htm

Brasil. Ministério do Desenvolvimento Regional - MDR. (2018a). Grupo 2 - Enquadramento. Cartas-consulta enquadradas. Brasília: MDR. Recuperado em 15 de julho de 2018, de http://mdr.gov.br/images/stories/ArquivosSEMOB/ArquivosPDF/lista-enquadradas_G2.pdf

Brasil. Ministério do Desenvolvimento Regional - MDR. (2018b). Programa Avançar Cidades - Mobilidade Urbana. Brasília: Ministério do Desenvolvimento Regional. Recuperado em 25 de setembro de 2019, de http://www.cidades.gov.br/mobilidade-e-servicos-urbanos

Correa, T., \& Gomes, N. (2018). Transporte Público Atual: condição do transporte público entre o Rio de Janeiro e a Baixada Fluminense. Revista Episteme Transversalis, 9(1), 135-145.

Gibson, C., Ostrom, E., \& Ahn, T. (2000). The concept of scale and the human dimensions of global change: a survey. Ecological Economics, 32(2), 217-239. http://dx.doi.org/10.1016/S0921-8009(99)00092-0. 
Gregório, L. S., \& Brandão, A. M. M. (2010). 0 Clima Urbano de São João de Meriti/RJ: um estudo aplicado à Análise do Campo Térmico e Ilhas de Calor. Revista Brasileira de Climatologia, 7, 21-36.

http://dx.doi.org/10.5380/abclima.v7i0.25623.

Harvey, D. (2014). Cidades rebeldes: do direto à cidade à revolução urbana. São Paulo: Martins Fontes.

Instituto Brasileiro de Geografia e Estatística - IBGE. (2019) Cidades@. Rio de Janeiro: IBGE. Recuperado em 24 de setembro de 2019, de https://cidades.ibge.gov.br/brasil/rj/seropedica/panorama

Magnoli, M. (2006). Em busca de outros espaços livres de edificação. Revista Paisagem e Ambiente - Ensaios, 21, 143-173. http://dx.doi.org/10.11606/issn.2359-5361.v0i21p141-173.

Maricato, E. (2001). Brasil, cidades - alternativas para a crise urbana. Petrópolis, RJ: Vozes.

Maricato, E. (2003). Metrópole, Legislação e Desigualdade. Estudos Avançados, 17(48), 151-167. http://dx.doi.org/10.1590/S0103-40142003000200013.

Nações Unidas. (2015). Transformando Nosso Mundo: Agenda 2030 para o desenvolvimento sustentável. Recuperado em 02 de julho de 2020, de https://nacoesunidas.org/wp-content/uploads/2015/10/agenda2030pt-br.pdf

O Globo. (2017). São João de Meriti abre as portas para o Mapa Estratégico do Comércio. Recuperado em 15 de julho de 2018, de https://oglobo.globo.com/brasil/sao-joao-de-meriti-abre-as-portas-para-mapa-estrategicodo-comercio-21315804

Observatório das Metrópoles. (2019) Base de Dados dos Município Brasileiros. Observatório das Metrópoles. Recuperado em 27 de setembro de 2019, de https://ibeu.observatoriodasmetropoles.net.br/sobre/

Portugal, L. (Org.), (2017). Transporte, mobilidade e desenvolvimento urbano. Rio de Janeiro: Elsevier.

Programa das Nações Unidas para o Desenvolvimento - PNUD. (2013) Atlas do Desenvolvimento Humano do Brasil. Recuperado em 23 de abril de 2018, de http://www.atlasbrasil.org.br/2013/pt/

Reyes, P. (2015). Projeto por cenários - O território em foco. Porto Alegre: Editora Sulinas.

Ribeiro, M. (2016). Desigualdades urbanas e desigualdades sociais nas metrópoles brasileiras. Sociologias, 18(42), 198-230. Recuperado em 25 de julho de 2019, de http://www.scielo.br/pdf/soc/v18n42/1517-4522soc-18-42-00198.pdf

Rolnik, R. (1995). O Que é Cidade? São Paulo: Editora Brasiliense.

Rubem, A. P. S., Moura, A. L., \& Gomes, C. S. F. (2014). Cenários Prospectivos no Apoio à Decisão: uma proposta de aprimoramento do método de Schoemaker. Relatórios de Pesquisa em Engenharia de Produção, 14(B5), 7080.

Santos, C. N. F. (1986). Está na hora de ver as cidades como elas são de verdade. Rio de Janeiro: IBAM.

Santos, M. O. G. (2013). O Planeamento por Cenários como Resposta das Organizações a Desafios Colocados na Época Actual. Évora: Unversidade de Évora. Recuperado em 3 de julho, de http://home.uevora.pt/ mosantos/download/PlaneamentoporCenarios_01Jun13.pdf

São João de Meriti. Prefeitura. (2006). Plano Diretor da Cidade de São João de Meriti, Lei Complementar N.o 089, de 21 de novembro de 2006. São João de Meriti: Prefeitura.

São João de Meriti. Prefeitura. (2019). São João de Meriti: Prefeitura. Recuperado em 3 de maio de 2019, de http://200.20.53.7/guanabara/Content/DOWNLOAD/Planos\%20completos/PMSB\%20-\%20SJ\%20MERITI.pdf

Schoemaker, P. J. H. (1995). Scenario planning: a tool for strategic thinking. MIT Sloan Management Review, $36(2), 25-40$.

Serpa, A. (2013). Lugar e Centralidade em um Contexto Metropolitano. In A. F. Carlos, M. L. Souza \& M. E. B. Sposito (Comp.), A produção do espaço urbano: agentes e processos, escalas e desafios. São Paulo: Contexto. 
Silva, L. (2017). Entre Laranja e Gente: notas preliminares sobre urbanização na baixada fluminense. In Anais do XVII ENANPUR. São Paulo: FAUUSP. Recuperado em 4 de julho de 2019, de http://anpur.org.br/xviienanpur/principal/?page_id=1298

Teixeira, E. H. S. B. (2006). Guia da mobilidade e desenvolvimento inteligente. Rio de Janeiro: Federação das Empresas de Transporte de Passageiros do Estado do Rio de Janeiro.

Tribunal de Contas do Estado do Rio de Janeiro - TCE. (2006). Estudo Socioeconômico de São João de Meriti. Rio de Janeiro: TCE. Recuperado em 15 de julho de 2018, de https://www.tce.rj.gov.br

United Nations. (2017) New Urban Agenda. USA: United Nations. Recuperado em 23 de abril de2018, de http://habitat3.org/wp-content/uploads/NUA-English-With-Index-1.pdf

Zegras, P. C. (2005). Sustainable urban mobility: exploring the role of the built environment (Tese de doutorado). Massachussets Institute of Technology, Massachussets.

Editor: Fábio Duarte

Recebido: Out. 10, 2019

Aprovado: Mar. 30, 2020 